\title{
PERANCANGAN SISTEM INFORMASI PENGELOLAAN BARANG DI GUDANG RPX DOMESTIC STUDI KASUS : PT. ANTAREJA PRIMA ANTARAN
}

\author{
Zahrah Nurlaila ${ }^{1}$, Febri Diandari ${ }^{2}$, Supono $^{3}$ \\ ${ }^{\mathbf{1 , 2 , 3}}$ Program Studi D III Manajemen Informatika, \\ Politeknik Pos Indonesia \\ 12zahrahnurlaila@gmail.com, ${ }^{2}$ febridiandari36@gmail.com, ${ }^{3}$ supono@poltekpos.ac.id
}

\section{ABSTRACT}

At this time PT. Antareja Prima Antaran or RPX often experience problems in warehousing such as calculating the time span of stored goods. It takes control of the activity of moving goods and documents to increase the efficiency of warehouse use so that the number and time span of goods are stored in a minimum value or according to the plan. In addition, based on the above problems, a warehouse checking system is made, the Early Warning feature to overcome overload in the warehouse, which is expected by customers not to need to be afraid and worried about the goods in the warehouse that will be sent through the RPX freight forwarder because there will be a checking facility for the goods arriving at the warehouse and the goods to be sent starting from the time the goods are entered and then processed to the place. Business Process Modeling Notation (BPMN) is a technique which enables all parties involved in the process to communicate clearly, correctly and efficiently. In this way, BPMN defines the semantic notation of the Business Process Diagram (DPB). DPB is a chart based on the 'Flowchart' technique

Keywords: Information System, Stock, Antareja Prima

\section{PENDAHULUAN}

RPX merupakan salah satu perusahaan yang bergerak dalam bidang Jasa Pengiriman Barang. Perusahaan tersebut melayani pengiriman barang ke seluruh wilayah Indonesia baik pengiriman barang door-to-door maupun port-to-port. Perusahaan tersebut memiliki gudang yang setiap harinya beroperasi sebagai transit barang yang akan di kirim melalui van courier dan bike courier. Saat barang datang dengan truk, barang tersebut diturunkan dalam truk. Lalu barang di scan dan di sortir menurut area atau rute. Barang yang telah di scan datanya akan masuk ke dalam computer dan di print untuk lokasi barang yang akan diatar. Jasa pengiriman barang merupakan suatu bentuk pelayanan publik yang menawarkan kemudahan dalam proses mengirim suatu barang dari satu kota ke kota lainnya dengan aman dan dapat dipertanggung jawabkan oleh pihak jasa tersebut. Dalam dunia bisnis, baik bagi perusahaan yang bergerak dalam bidang manufaktur maupun jasa, tentu sangat penting dalam proses operasional perusahaan, kegiatan memproduksi menjadi langkah awal untuk suatu perusahaan memperoleh satu produk.

Produk tersebut harus dijaga dengan baik agar dapat sampai ditangan konsumen, dan untuk menjaga produk tersebut diperlukan gudang sebagai tempat penyimpanan barang agar tetap aman. Berdasarkan artikel Prokal.com di tengah kondisi arus mudik saat ini, pengiriman paket barang belanjaan online di penyedia jasa pengiriman mulai overload. sejak memasuk hari ke20 Ramadan, volume barang yang datang memang meningkat, sehingga proses pengantaran barang hingga ke konsumen ikut terganggu. hal ini terjadi setiap tahunnya menjelang Lebaran, namun angka peningkatannya tidak selalu sama. [Prokal.com, 2018] Pergudangan yang dimaksud berfungsi untuk menyimpan barang hasil produksi dalam jumlah dan rentang waktu tertentu yang kemudian didistribusikan ke lokasi yang dituju berdasarkan permintaan.

\section{METODE}

Penelitian ini dilakukan dengan beberapa tahapan yaitu: perancangan Sistem Informasi. Metodologi Waterfall digunakan untuk pengerjaan dari suatu sistem yang akan dilakukan secara sistematis dan berurutan. Disebut dengan Waterfall karena tahap demi tahap harus menunggu selesainya tahap sebelumnya dan berjalan berurutan. Berikut ini merupakan gambar ilustrasi Metodologi Waterfall :

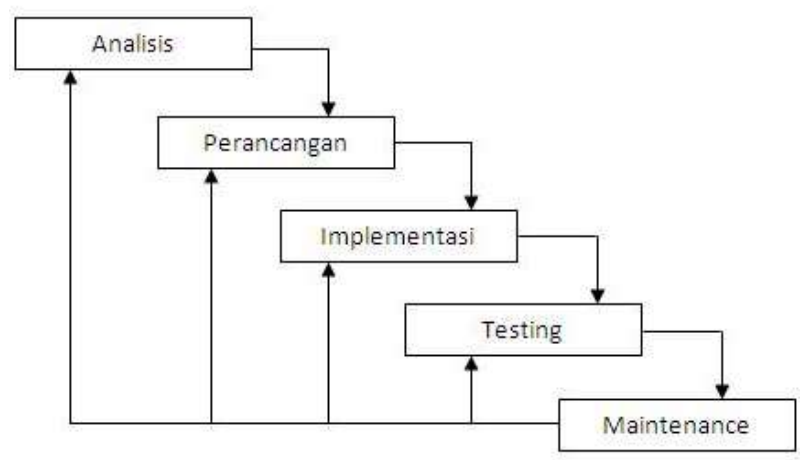

Gambar 1. Waterfall model (Sumber: Kadir, 2003) 


\section{ANALISIS SISTEM}

Analisis umum dapat dilakukan dengan enggambarkan rantai nilai beserta penjelasannya. Rantai Nilai (Porter) adalah model yang digunakan untuk membantu menganalisis aktifitas-aktifitas spesifik yang dapat menciptakan nilai dan keuntungan kompetitif bagi organisasi.

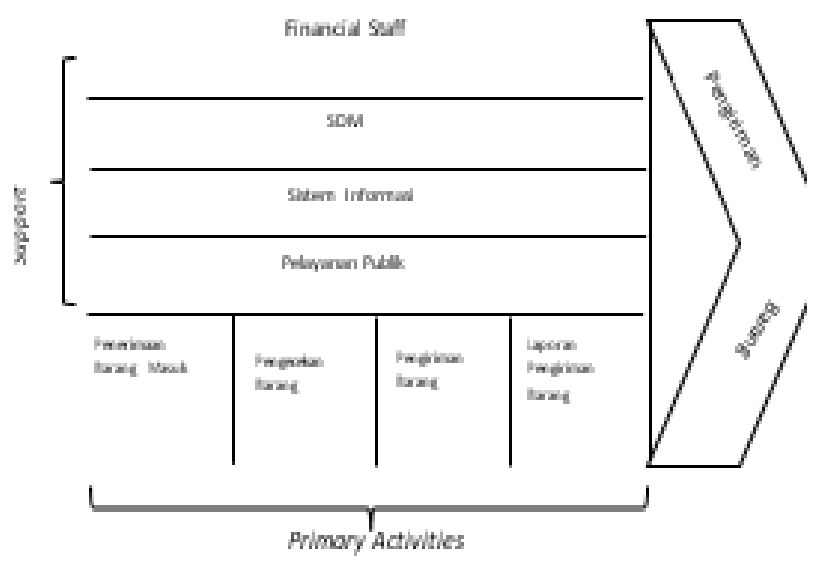

Gambar 2 Rantai Nilai Porter
Aktifitas objek yang dianalisis adalah proses pengiriman barang di RPX Jl. Sampurna No. 12, Analisis dokumen dilakukan terhadap aktifitas yang sudah dipilih menjadi objek analisis. Analisis khusus ini bisa berupa deskripsi pembahasan tentang business user, business process, business data (misal terdiri dari kamus data, analisis dokumen, analisis pengkodean, dan analisis laporan), business rule, business problem and solution serta business plan. Adapun fungsi dari BPMN adalah untuk mempermudah penggambaran aliran data yang berupa dokumen sistem yang sedang berjalan. Berikut ini BPMN sistem untuk proses bisnis yang sedang berjalan.

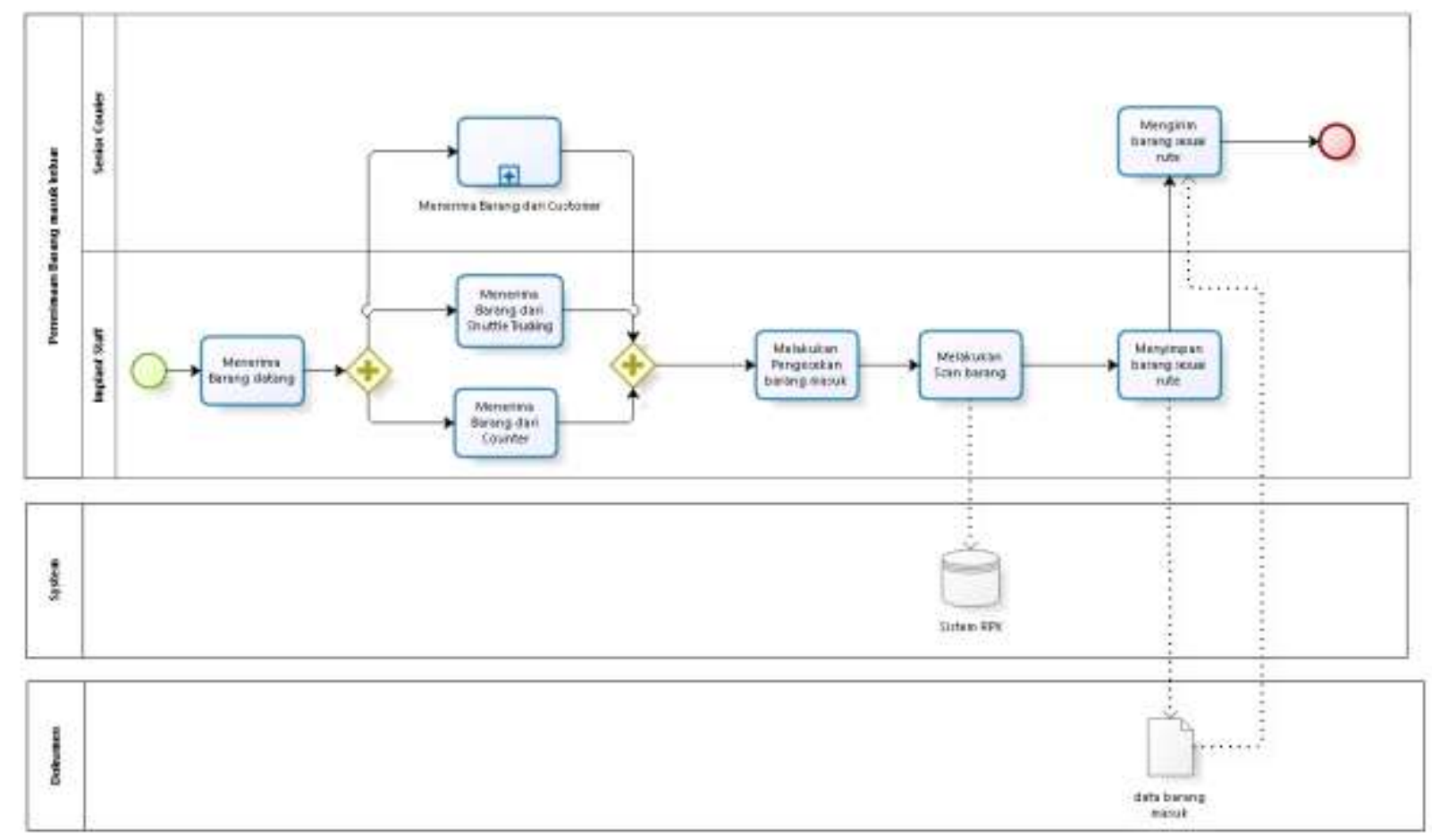

Gambar 3 BPMN Proses Penerimaan Barang Masuk dan Keluar

Deskripsi BPMN penerimaan barang masuk keluar :

1. Barang masuk, ada tiga pilihan pemesan datang langsung ke kantor (counter), pemesan mengirim barang yang melalui courier, dan mengirim barang dari shuttle.

2. Implant Staff menerima barang dan melakukan pengecekan setiap barangnya.

3. Barang di scan kemudian hasil scan masuk ke dalam sistem.
4. Barang disimpan sesuai rute masing-masing, kemudian dokumen barang masuk akan diberi kepada courier.

5. Senior Courier akan melakukan pengiriman sesuai tujuan rute. 


\section{HASIL DAN PEMBAHASAN}

\section{Perancangan Sistem}

Proses checking tarif dan trackin barang pada PT.Antareja Prima Antaran atau RPX sering mengalami kendala dalam pergudangan seperti menghitung rentang waktu barang disimpan. Dibutuhkan control aktivitas pengerakan barang dan dokumen untuk meningkatkan efisiensi penggunaan gudang agar jumlah dan rentang waktu barang disimpan dalam nilai minimum atau sesuai perencanaan Selain itu Berdasarkan pemasalahan diatas, maka dibuat adanya sistem pengecekan pergudang, fitur Early Warning untuk mengatasi overload dalam gudang yang diharapkan pelanggan tidak perlu takut dan khawatir mengenai barang digudang yang akan kirim melalui jasa pengiriman barang RPX karena akan tersedia fasilitas pengecekan dari barang datang di gudang dan barang yang akan dikirim.

\section{Use Case Diagram}

Perancangan sistem ini meliputi Use Case diagram, Activity diagram, Sequence diagram, Class diagram untuk menggambarkan sistem informasi yang akan dibangun.

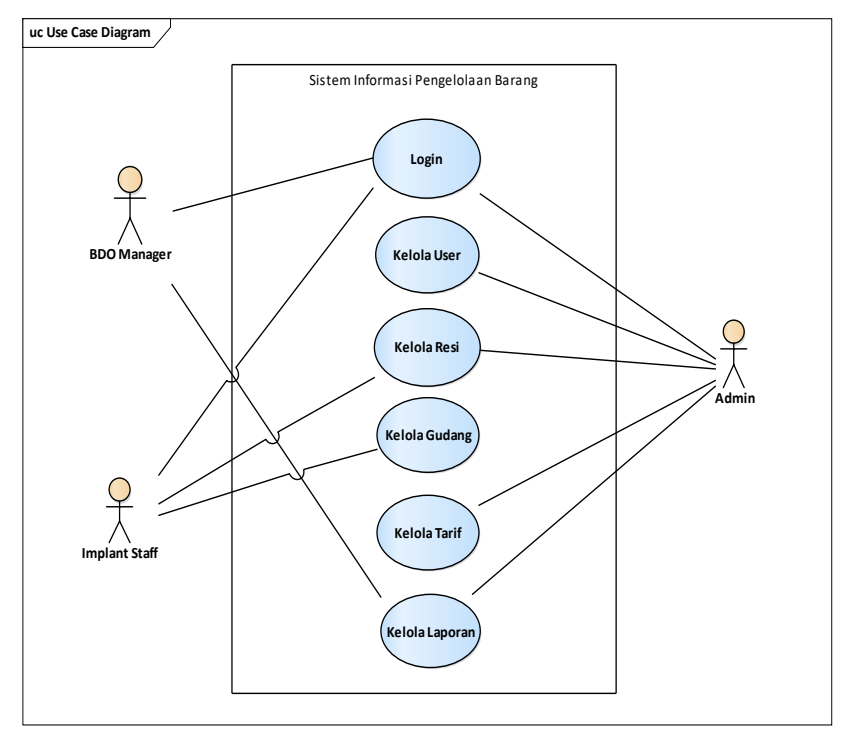

Gambar 4 Use Case Diagram

Berdasarkan gambar 4 Use Case diagram Sistem Informasi Pengecekan Barang di Gudang RPX PT. ANTAREJA PRIMA ANTARAN memiliki 3 aktor yaitu Admin, BDO Manager, dan Implant Staff. Dan memiliki 6 use case yaitu validasi login, kelola user, kelola resi, kelola gudang, kelola tarif, dan kelola laporan.

\section{Class Diagram}

Class diagram adalah pemodelan yang menggambarkan keterkaitan atau hubungan antar kelas yang berisi atribut dan operasinya. Berikut class diagram dari sistem yang dibangun:

Berdasarkan Gambar 4 Class Diagram Sistem Informasi Pengelolaan Barang di gudang RPX memiliki 6 class yang saling terhubung satu dan lainnya. Untuk get data dari laporan.

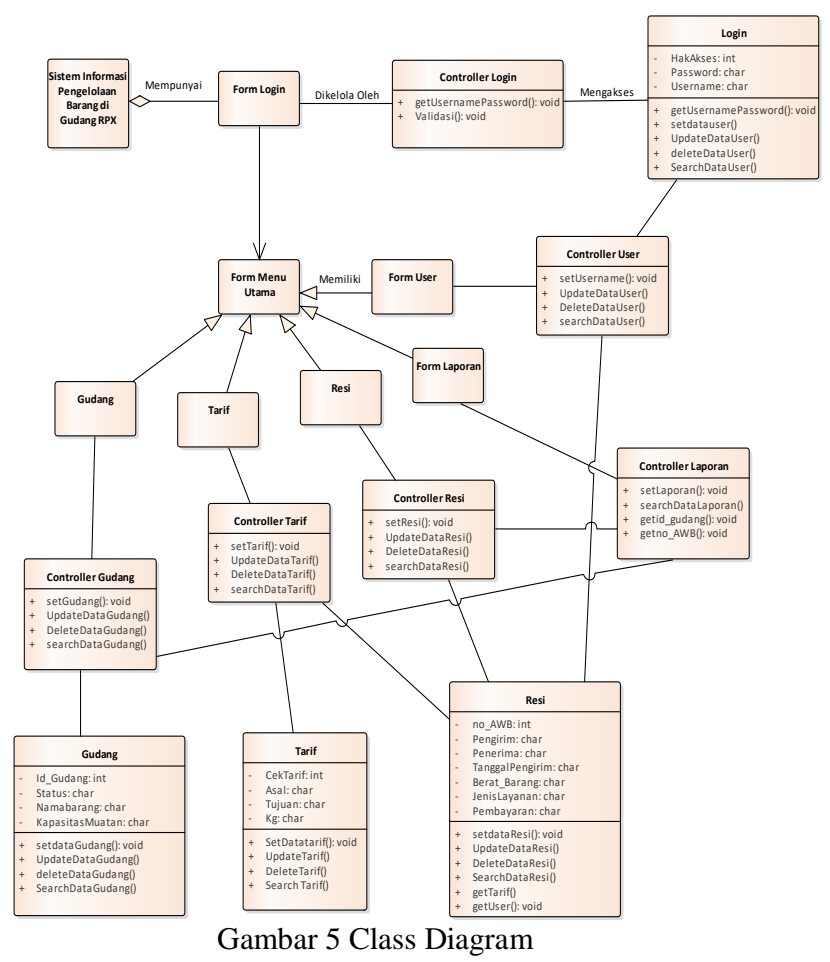

\section{Perancangan Menu}

Perancangan menu meggambarkan menu-menu yang ada pada Sistem Informasi Pengelolaan Barang di gudang RPX. Perancangan menu ini terdiri dari menu halaman Admin untuk mengelola user, mengelola resi dan mengelola tarif. Halaman Implant Staff untuk mengelola resi, dan mengelola gudang. Halaman BDO Manager untuk melihat laporan. 


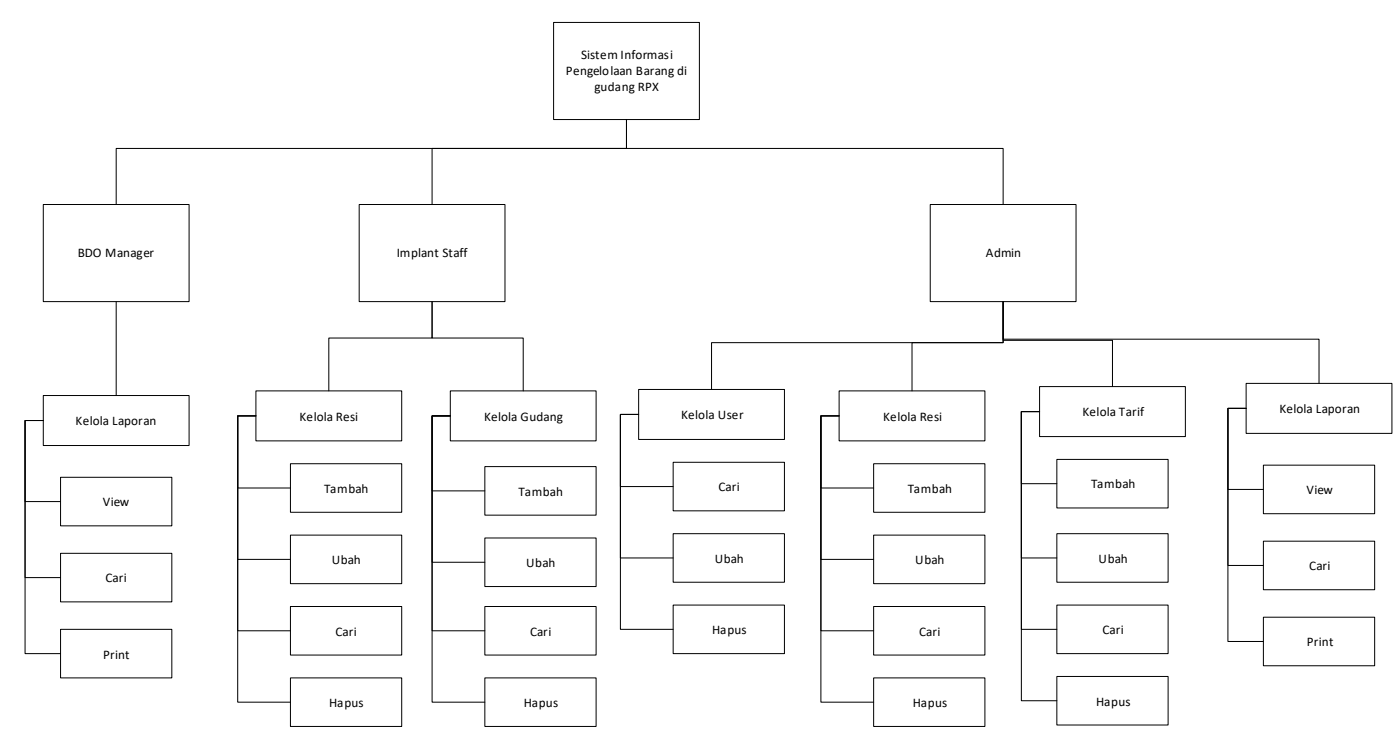

Gambar 6 Perancangan Menu

\section{Perancangan Antar Muka}

Perancangan antarmuka menggambarkan tampilan dari aplikasi yang akan dimplementasi berdasarkan untuk Sistem Informasi Pengelolaan Barang di gudang RPX. Berikut merupakan perancangan antarmuka halaman utama.

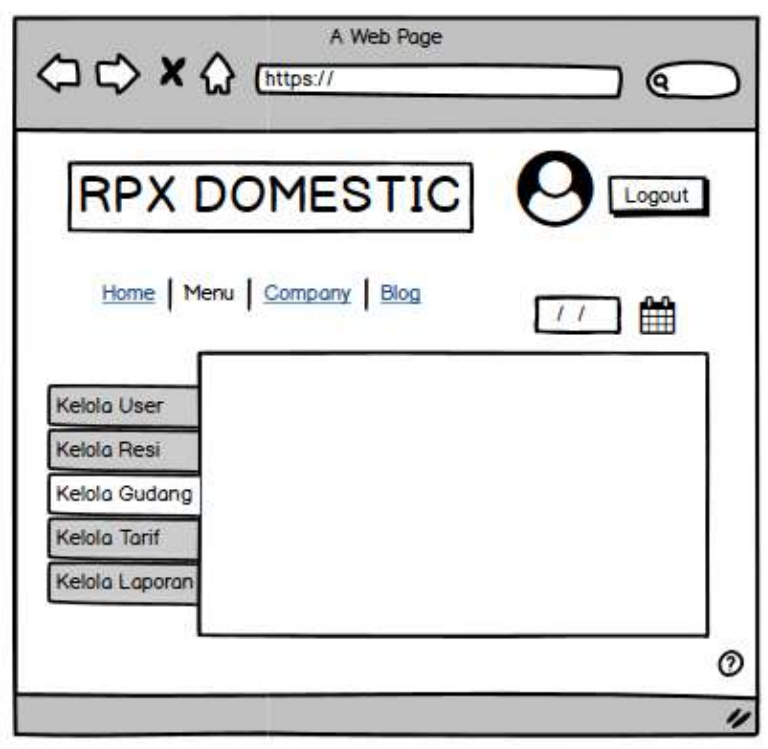

Gambar 7 Antar Muka Halaman Menu

Perancangan Sistem Informasi Pengelolaan Barang di Gudang RPX menggunakan pendekatan perancangan berbasis objek yaitu dengan menggunakan UML dalam hal ini digambarkan dalam Use Case Diagram. Secara umum perancangan sistem ini dimulai dari: (1) implant staff menginput data resi dan gudang, (2) setelah itu implant staff dapat mengecek ststus barang di gudang melalui website yang disediakan.

\section{KESIMPULAN}

Setelah melakukan analisis dan perancangan Sistem Informasi Pengelolaan Barang di gudang RPX, diperoleh beberapa kesimpulan yaitu :

1. Telah dihasilkan rancangan sistem informasi yang menyediakan fitur pendataan barang masuk keluar di gudang.

2. Telah dihasilkan rancangan sistem informasi yang menyediakan fitur penumpukkan barang pada stok barang.

\section{DAFTAR PUSTAKA}

[1] [Prokal.com (2018)] Pengiriman Paket Barang Overload. Dipetik Juni 2018, dari https://kaltara.prokal.co/read/news/19444-pengirimanpaket-barang-overload.html

[2] [Kadir. (2003)]. Metode Pengembangan Sistem Waterfall. Dipetik Maret 2018, dari https://agusdar.wordpress.com

[3] [Ade Hendini. (2016)] Pemodelan UML Sistem Informasi Monitoring Penjualan Dan Stok Barang, Dipetik Desember 2016, dari https://ejournal.bsi.ac.id/ejurnal/index.php/khatulistiwa /article/view/1262

[4] [Porosilmu.com(2016)] Pengertian dan Fungsi Gudang, dari https://www.porosilmu.com/2016/11/pengertiandan-fungsi-gudang.html\#

[5] [leskompi,2019] Dzikri Azqiya (2019). Dipetik Agustus, 2019, dari Mengenal Arti Dalam Pengiriman dari

https://www.leskompi.com/artioverload/\#Mengenal_M aksud_Overload_Dalam_Pengiriman 